\title{
Continuity of natural science education as a condition for training specialists of the agrarian sector of the economy
}

\author{
Valentina Abraukhova ${ }^{1, *}$, Tatiana Vlasova ${ }^{1}$, Anastasiya Zimovetc ${ }^{1}$ \\ ${ }^{1}$ Don State Technical University, 1, pl. Gagarina, 344000, Rostov-on-Don, Russia
}

\begin{abstract}
This article is devoted to the study and construction of a model of continuous natural science education. The article considers the concept of "continuous learning" in the field of natural science. Special emphasis made on the specificity and amount of content at different levels of education: preschool, primary, secondary general and secondary professional, additional for training personnel in the agricultural sector. The foreign and domestic experience of lifelong learning training practices is analyzed in detail. The social effect of the results of the implementation of the projects is characterized by the creation of a modern industry of continuing education for children and new forms of lifelong education, creates a space for tests, forms the choice of life path and professional development of staff for the agricultural sector.
\end{abstract}

\section{Introduction}

Changes in society, the accelerated accumulation of knowledge has advanced a new approach to education and training. Continuing education in the world is considered as a holistic process of development of creative potential of personality and all-round enrichment of its spiritual world. The discovery of new knowledge, development of new technology requires constant compliance specialists modern requirements. The formation of a specialist consists of successively elevated levels of change in social status, passing through stages of specially organized training.

In the education strategies of UNESCO on lifelong learning, puts forward the following definition: the ability to be educated throughout life, the dominance of the idea of selflearning and self-development, the acquisition of special skills, development of their creative potential. Education, covering all vital areas have been defined as "life-wide". Research A. Green identify features of the education as synergy or complementarity between the official (formal), informal (non-formal) and informal (informal) education [1].

The concept of lifelong learning is now necessary to focus on individual growth and daily life, to create a collective ideology of lifelong learning based on the improvement of individual consciousness [2].

Approaches and methods may vary, and depending on the approach of scientists and the countries they study, we will consider all the options. The article by Zhiwei Chen and Ying

*Corresponding author: childrenpalace@ mail.ru 
Liu describes life-long learning as based on the influence on motivation and factors by comparing interviews with Chinese and American citizens from different social strata, gender, age, professions, educational levels and geographical location, etc.

Using biographical research and sound theory through open, axial, and selective coding, we have found that the main motives and factors influencing learning in each country can be divided into four groups: Family, individual, social, and educational factors Chinese lifelong learning embody a type of "social utilitarianism", while Americans have a particular "individual interests and Hobbies" [3].

The theoretical foundations of lifelong learning in the EU designated as a model of the three priorities: smart growth (developing an economy based on knowledge and innovation); sustainable growth (promoting "green" ecological and competitive economy) inclusive growth (promoting an economy with high employment and social and territorial cohesion) [4].

\section{Materials and Methods}

The logical purpose of this study was to develop an effective model of formation and development of the personality of the professional agricultural sector. The unity of purpose of lifelong education assumes maximum variability in the construction of individual trajectories of student's free choice of types of educational institutions, forms and technologies of education.

Starting at pre-primary level of education, a program focused on the development of visual-figurative and verbal-logical thinking. It is vitally important to introduce a child to the world of experimentation with experimenting with the animate and inanimate nature, to create conditions for creativity, in which he will show an interest in this area of expertise. On the basis of kindergarten № 83 and school No. 111 in the city of Rostov-on-don was organized by activity for the implementation of the program "STEM education of children of preschool and younger school age", the authors Volosovets T. V., Markov V. A., Averin S. A. [5]. For the experiment have been chosen the area of natural science. The program is based on applied approach. Children master project, experimental and research activities, to obtain new and objective knowledge, to adapt children to the modern educational environment of all levels of education.

In this program, the world studied by the child through play and experimentation. Studying the features of life of living beings, properties of water, air, sand, clay, soil, stones, their interactions with each other and with the environment, children gain an invaluable knowledge in their experimental way. Such knowledge remains for life, since the child not only listened to the story of an adult, but personally observed the process, participated in it, was emotionally involved, built assumptions, saw the result.

Properly equipped research laboratory with proper introduction to the educational process and provides educators with the ability to fill classes in acquaintance with world around experiments with animate and inanimate nature, to arouse children's interest to experimental activities to inculcate the basic skills of research. The implementation of educational research and projects is carried out under the guidance of teachers and independently on a variety of topics: "The Influence of modern technical devices on the organism of a child", "Experimenting with living and non-living nature", "Water-basis of life on Earth", "Second life of plastic", "Second life of things", "Purity of nature begins with me", "Healthy nutrition", "rare and endangered plants and animals" and others. At the pre-school and school levels, it is important that natural science programs are combined with supplementary education programs of additional education of natural-scientific orientation are implemented in the Children's University DGTU and the Don Academy of Sciences of young researchers of the Children`s Palace of Rostov-on-Don. Presentation of results of research, creative activities 
of students are the annual scientific and practical conference of the Don Academy of Sciences of Young Researchers (of DASYR), student conference "Week of science", conference "Maxi-um", all-Russian Olympiads, contests, conferences. The social effect of the project results is characterized by the creation of a modern industry of additional education for children and new forms of lifelong learning education, creates space for tests, generates the choice of a life path

More than $90 \%$ of high school students, underwent questionnaire survey in the Palace of children, consciously approach to the selection of areas of activity, they have dominated the status of professional identity and formed competence, educational mobility:

1. Socio - communicative - willingness to socialization in the modern society;

2. Educational readiness to the scientific, systematic knowledge of the world, selfimprovement and self-education;

3. Scientific - high level of basic knowledge on natural-scientific profile;

4. Value-semantic readiness to knowledge and productive activities.

Annually diagnosis of the participants of the Don Academy of Sciences of Young Researchers, revealing their motivation, possible difficulties in writing a research paper, evaluating the outcomes of their participation.

Educator should take into account that in organizing and conducting research for students the greatest difficulties were represented: Working with primary sources (scientific articles, monographs, etc.); independent goal setting; mobilization of efforts to achieve educational and cognitive goals. $62 \%$ of students surveyed said that in the process of conducting research for the DASYR conference, they learned to define and explain concepts; analyze and highlight the main thing; compare; match; to systematize; specify generalize; ability to see contradictions; prove and refute. Almost half of the students (48\%) have mastered scientific speech and terminology. $45 \%$ of speakers realized their responsibility for the quality of the project. It is noteworthy that $76 \%$ of participants of DASYR are completely or partially satisfied with their success in research activities and fully or partially satisfied with their success in research.33\% of young researchers expressed a high degree of independence, self-confidence. They themselves decided to participate in a scientific conference, guided by internal motivation, pragmatic, ambitious (to be the first, to lead). It was also confirmed that teachers of additional education may be interested in, enthrall students with research activities. It was the teacher (scientific curator) in $50 \%$ of the sampling who influenced their decision to take part in the DASYR. Dynamics of preferences of various types of activities of adolescents DASYR for 2017-2018 and 2018-2019 in figure 1.

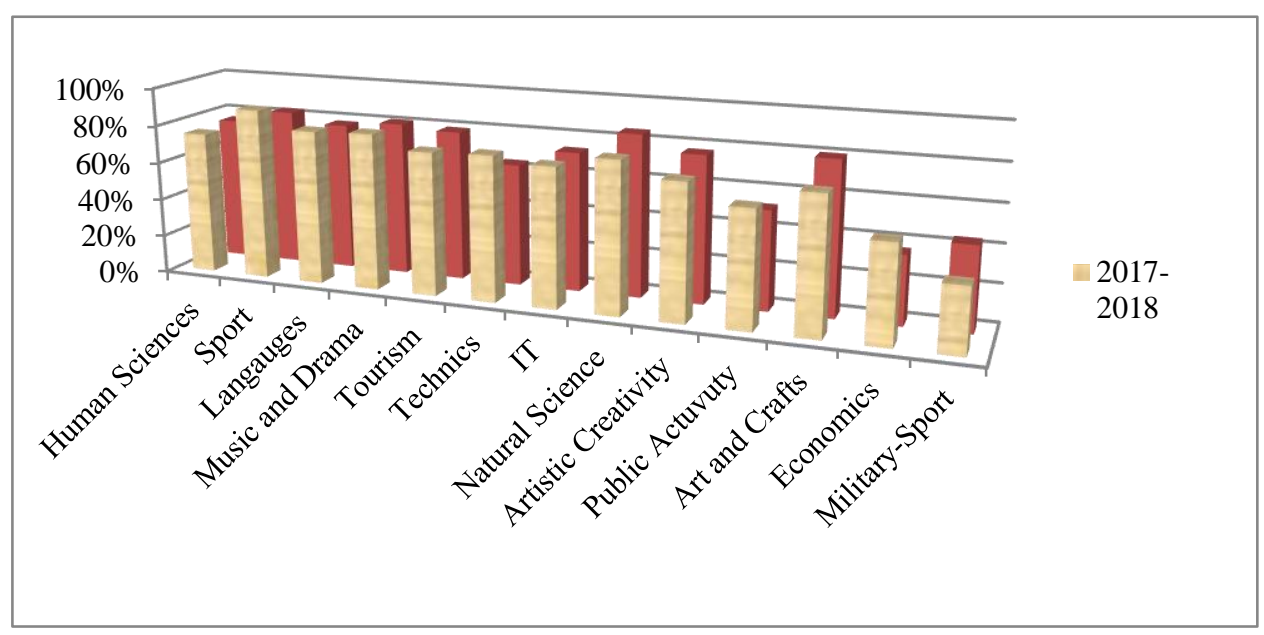

Fig. 1. Dynamics of interests of adolescents. 
The diagram illustrates a marked growth in the interest of adolescents to the following activities: science, tourism, art and craft work, military and sports activities.

The structure of the pupils learning education presents a variety of motives. 50\% (119 people) of students are very practice-oriented, i.e. they are in the classroom desire to master skills certain activities children's association. Also, many adolescents dominated by the hedonistic motive - $63 \%$ (151 people), that is, learners get pleasure from what you do. $35 \%$ of adolescents ( 84 people) in the basis of their desire to attend is informative motive, they want to learn something new, expand their horizons. 14\% (34 people) of students are attracted to the friendly atmosphere of children's community where you can find friends and fellowship. The motive of self-actualization, personal growth is observed in 23\% (56 persons) of the pupils. $10 \%$ ( 25 persons) guided by the motive of professional self-determination (i.e., the classes help them prepare for their future profession). $11 \%$ (27 people) think that the lessons can benefit them in the future. $3 \%$ ( 6 people) believe that children's associations have the opportunity to write their research work and also work on your rhetorical skills.

Research creativity personal development abroad in consonance with the phenomenology of creativity. Known, the knowledge of international creative associations - Society Leibniz, DIPF, EAICY, DASYR and many others, realizing this paradigm.

Building next step lifelong education, we turned to the experience of the Centre for continuing agricultural education of the Tyumen region, where the use of dual model of training in professional educational programs of secondary professional education.

Dual training is a kind of vocational education, in which the practical part of the training takes place in the workplace, and the theoretical part on the basis of educational organization.

Developing the economy and improving the standard of living in the region. What are the main achievements of this system in the course of the survey of the learning systems of secondary vocational education? The implementation of the dual system brings the content of education into line with the current level of production; acquaints students with the corporate culture of the enterprise, its features; adapts the graduate in a new labor collective; attracts highly qualified engineering and technical personnel of the enterprise to the educational process as specialists (employers).

This model will be effective not only for the secondary vocational education system. On the principle of duality, it is possible to build cooperation with employers by creating a supervisory board; implementation of joint research projects; modernization of existing facilities; construction and equipment of laboratories (training and production complex); material support of teachers, students; opening training sites at the enterprise.

\section{Results}

Determining the result of this study was the development of an effective model for the formation and development of the personality of a professional in the agricultural sector. The model includes educational levels of preschool, primary, secondary general, secondary vocational and higher. The unity of the goals of lifelong education is combined with the variability of education, the variety of types of educational institutions, forms and technologies of instruction. In the practice of institutions, we have identified modern effective models such as programs "STEM-education of children of preschool and primary school age", programs of design and research activities - for secondary general education and dual education - for secondary vocational and higher education 


\section{Discussion}

For the qualitative development of lifelong learning, each country develops its technological model, which will ensure the process of learning throughout the whole life by constant technical support. For example, in Malaysia for the development of human capital, students should be involved in the learning community. Learning communities apply a constructivist approach to knowledge, in which knowledge is not just "opened up", but socially designed. As a result, the training can be divided into four main categories: formal training (activity that is conducted in formal schools, which leads to some form of accreditation or qualification), informal learning (learning that occurs outside the formal educational context, where the purpose of training does not necessarily lead to a qualification), personal, when people participate in activities to acquire new skills or knowledge in certain areas related to their work or personal growth (private lessons for examinations, technical courses, further education, work-related, training, public programs and other educational activities organized by public, private or non-governmental organizations); non-formal learning, which includes, as a rule, unstructured learning activities to meet the need for knowledge of certain things. This is a random training includes unplanned and unintentional learning outcomes that are directly related to other activities in which students can suddenly discover the connection between different objects that gives them value [6].

Lifelong learning reflects the same way as European communication, which includes six basic elements: partnerships, understanding the need for learning in society, knowledgebased, adequate funding, facilitating access to learning opportunities, creating a learning culture and the pursuit of excellence [7]. In Norway, in the reasoning of lifelong learning, the emphasis is on creating the necessary conditions for understanding professionalism in early childhood and school education [8].Lifelong learning is based on the concept of Delors (learning knowledge, learning to do, learning to live together, learning as cognition-education [9].Lifelong learning is a problem for companies, especially for small and medium enterprises. As manufacturing systems become increasingly complex and software intensive, workers often have diverse skills. Digital Factory-Academy provides a structure with concrete examples for companies to plan and implement training for current and future employees. CPS (cyber physical system) supports educational and research collaboration between academia and industry. This local implementation of the universal learning environment supports problem solving by introducing non-standard, practical and industry problems [10]. The physical learning environment is often considered a secondary element of education. Therefore, we once again draw attention to the experience of colleagues who considered the following research questions: What role does the physical learning environment play in the educational process? How can we adapt the physical learning environment to 21 st century education? Based on the obtained data, a model of the ideal school environment, called MoPLE21, is presented and can be viewed on the Internet as an appendix to this document at https://mople21.org. The results show that the physical environment is an important and often underestimated factor in a well-designed school environment can play a significant role in teaching and learning in the 21 st century. Finally, MoPLE21 is seen as an interdisciplinary tool for theorists and education professionals to design, evaluate, and use everyday in educational environments[11].

Studies based on applications from different European countries with a focus on the role of third-age universities (U3A) as a new excellence for lifelong learning in maintaining active citizenship in the economic and cultural fields for a changing society and "active aging", not the term "aging," defined as something due to deficiency [12]. Aging is associated with a decrease in curiosity.

- Retained curiosity helps older people maintain emotional well-being.

- Curiosity also protects against cognitive and physical decline with age. 
- Dopaminergic and noradrenergic mechanisms support these protective effects.

Curiosity is a fundamental part of human motivation that supports various types of intellectual human behavior - from early childhood education to scientific discoveries. However, little attention has been paid to the role of curiosity in an aging population. By collecting extensive but rare neuroscientific and psychological literature on curiosity and related concepts (such as seeking novelty in older people), we suggest that curiosity, although decreasing with age, play an important role in maintaining cognitive function, mental health, and physical health is not only in older people. We define the dopaminergic reward system and the noradrenergic system as key brain systems involved in the processing of curiosity, and discuss how these brain systems contribute to the relationship between curiosity and adaptive aging [13].

\section{Conclusions}

DSTU (Don State Technical University) today is the largest scientific and educational center of the South of Russia, where the priority tasks are the development of the research infrastructure, focusing on a qualitatively new level of training for practitioners whose knowledge and competencies meet the current needs of the largest enterprises in the region.

The university unites educational organizations of different levels under its foundation. The structure of the university includes kindergartens, a gymnasium, a lyceum, colleges, a department of further education, a Children's University, etc. The university has a resource base for building continuous models of specialized education.

\section{References}

1. A. Green, Lifelong Learning: What does it Mean? (2016) https://www.researchgate.net/publication/224767020

2. V. Murgul, Procedia Engineering 117, 808-818 (2015) doi:10.1016/j.proeng.2015.08.145

3. Z. Chen, Y. Liu, IJofER 95, 13-25 https://www.sciencedirect.com/science/article/pii/ S0883035518320305\#

4. O. Kaspars, C. Sarma, A. Kapenieksa, G. Zarifisb, PCS 77, 104-112 (2015) https://www.sciencedirect.com/science/article/pii/S18770509 15038764

5. T. Volosovets, V. Markova, S. Averin, STEM-education for children of preschool and primary school age (BINOM, Moscow, 2019)

6. Y. Buntata, N. Puteha, S. Azemana, A. Nasira, N. Iahadb, M. Azizc, PSandBS 15.93, 1541-1545 (2013)

7. M. Laal, A. Laal, PSandBS 47, 1562-1566 (2012)

8. H. Braathe, A. Otterstad, PSandBS 19.46, 2503-2508 (2012)

9. N. DuĞă, E. Rafailă, PSandBS 127, 801-806 (2014)

10. M. Lanza, A. Lobova, K. Katajistob, P. Mäkeläb, PM 23, 189-194 (2018) doi.org/10.1016/j.promfg.2018.04. 015.

11. C. Szpytmaa, M. Szpytmab, MoPLE21 34 (2019)

12. E. Günder, PSandBS 17.116, 1165-1169 (2014)

13. M. Sakakiab, A. Yagib, K. Murayamaab, N\&BR 18.88, 106-116 (2018) 